\title{
Spirulina Supplementation, Sire Breed, Sex and Basal Diet Effects on Lamb Intramuscular Fat Percentage and Fat Melting Points
}

\author{
B.W.B. Holman ${ }^{1}$, A.R. Flakemore ${ }^{2}$, A. Kashani ${ }^{3}$ and A.E.O. Malau-Aduli ${ }^{4}$ \\ ${ }^{1}$ New South Wales Department of Primary Industries, Centre for Red Meat and Sheep \\ Development, Australia \\ ${ }^{2,3,4}$ Animal Science and Genetics, Tasmanian Institute of Agriculture, School of Land and Food, \\ Faculty of Science, Engineering and Technology, University of Tasmania, Australia \\ ${ }^{4}$ School of Veterinary and Biomedical Sciences, Faculty of Medicine, Health and Molecular Sciences, \\ James Cook University Townsville, Australia
}

Correspondence should be addressed to: Malau-Aduli; Aduli.MalauAduli@utas.edu.au

Received date: 21 May 2014; Accepted date: 10 July 2014; Published date: 26 September 2014

Academic Editor: Ping Xie

Copyright (C) 2014. B.W.B. Holman, A.R. Flakemore, A. Kashani and A.E.O. Malau-Aduli. Distributed under Creative Commons CC-BY 3.0

\begin{abstract}
The effects of Spirulina supplementation, sire breed, sex and basal diet on intramuscular fat percentage (IMF) and fat melting point (FMP) in crossbred and purebred Merino lambs were investigated. Over two consecutive years, a total of 48 lambs was randomly allocated into feeding trials that utilised either ryegrass or Lucerne hay basal diets. Each treatment group had 8 lambs balanced by sire breed (Black Suffolk, Dorset, Merino, White Suffolk), sex (ewes, wethers), and Spirulina supplementation level (CONTROL - unsupplemented, LOW $50 \mathrm{ml}$, MEDIUM $-100 \mathrm{ml}$, and HIGH $-200 \mathrm{ml}$ ). Each feeding trial lasted for 9-weeks after 21 days of adjustment. Post-slaughter, IMF content of the Longissimus dorsi et lumborum muscle was determined using solvent extraction and FMP measured using the 'slip-point' method. Spirulina supplementation level influenced both IMF content and FMP in which MEDIUM Spirulina supplementation led to a decrease in IMF $(1.98 \%)$ and FMP $\left(42.97^{\circ} \mathrm{C}\right)$ compared to $3.18 \%$ and $44.44^{\circ} \mathrm{C}$, respectively, in the LOW supplementation treatment group. Sire breed was a significant source of variation in FMP as purebred Merinos had the highest $\left(45.63^{\circ} \mathrm{C}\right)$ and Black Suffolk crossbreds the lowest $\left(41.53^{\circ} \mathrm{C}\right)$. Ewe lambs had higher IMF than wether lambs (2.52 vs $2.12 \%$ ). Lambs on the ryegrass basal diet had lower IMF and FMP than their counterparts on Lucerne. Significant interactions between sire breed and supplementation level suggest a variety of nutritional management combinations that prime lamb producers can utilise to optimise meat quality for increasingly health-conscious consumers.
\end{abstract}

Keywords: Arthrospira platensis, Spirulina, meat quality, dual-purpose sheep

Cite this Article as: B.W.B. Holman, A.R. Flakemore, A. Kashani and A.E.O. Malau-Aduli (2014), " Spirulina Supplementation, Sire Breed, Sex and Basal Diet Effects on Lamb Intramuscular Fat Percentage and Fat Melting Points", International Journal of Veterinary Medicine: Research \& Reports, Vol. 2014 (2014), Article ID 263951, DOI: 10.5171/2014. 263951. 


\section{Introduction}

Australian dual-purpose lamb production must cater to consumer demands for a healthier product of high eating quality. Consequently, much research has focused on producing a leaner meat cut with increased levels of unsaturated fats. Meats rich in unsaturated fatty acids and low fat melting point (FMP) have been associated with increased palatability (Siebert et al., 2000) and consumer health benefits from reduced risks of cardiovascular disease (Woods \& Fearon, 2009). However, unbridled focus on lean meat production may have a negative impact on intramuscular fat percentage (IMF) which is closely aligned with the fundamental meat eating qualities of tenderness and juiciness (Hopkins et al., 2007, McPhee et al., 2008). Fortunately, FMP and IMF can both be manipulated by strategically managing the basal diet and supplementary feed intake of lambs.

Spirulina (Arthrospira platensis) is a cyanobacterium which has been trialled as a supplementary feed in many animal species (Holman \& Malau-Aduli, 2013). Its nutrient-rich composition includes essential fatty acids, amino acids and carotenoids (Table 1), and makes it an ideal dual-purpose lamb supplement. Yet, to the best of our current knowledge, the effect of Spirulina supplementation on FMP and IMF has only been trialled in rabbits (Peiretti \& Meineri, 2011). Therefore, our objective was to evaluate the effect of Spirulina supplementation level and its interactions with sire breed, sex and basal diet on IMF and FMP in purebred and crossbred Merino lambs. We hypothesised that there will be significant reduction in IMF and FMP in the Longissimus dorsi et lumborum muscle of grazing lambs with increasing levels of dietary Spirulina supplementation.

\section{Materials and Methods}

This study was conducted at the University of Tasmania Farm, Cambridge, Hobart, Australia and approved by the University of
Tasmania Animal Ethics Committee in accordance with the 1993 Animal Welfare Act and the 2004 Australian Code of Practice for the Care and Use of Animals for Scientific Purposes.

Over two consecutive years (2011-12), 16 rams belonging to 4 sire breeds were mated with approximately 1600 purebred Merino ewes in a 1:100 mating ratio at the University Farm in separate paddocks to generate $F_{1}$ progeny. The progeny was identified using National Livestock Identification ear tags and weaned onto ryegrass pastures at 12 weeks of age. At 6 months old, 24 lambs were randomly selected for each feeding trial using ryegrass pasture (2011) and Lucerne hay basal diets (2012). Feeding trials continued over 9-weeks after 21 days of adjustment.

Spirulina powder was purchased (TAAU, Darwin, Northern Territory, AUS) and made into a water suspension using a 1:10 $\mathrm{w} / \mathrm{v}$ ratio - Spirulina $(\mathrm{g})$ : water $(\mathrm{ml})$. Each lamb was directly provided with its assigned Spirulina supplementation level daily via oral drenching.

Ryegrass pasture: Random lamb allocation into the following treatment groups was undertaken: CONTROL (0mL), MEDIUM $(100 \mathrm{~mL})$ and HIGH $(200 \mathrm{~mL})$ Spirulina supplementation levels balanced by lamb sire breed (Black Suffolk, Dorset, Merino and White Suffolk) and sex (ewes and wethers). All lambs had ad libitum access to drinking water, $150 \mathrm{~g}$ of barley grains per day and were run as a single flock on ryegrass pasture.

Lucerne hay: Treatment groups of Spirulina supplementation levels were: CONTROL $(0 \mathrm{~mL})$, LOW $(50 \mathrm{~mL})$, MEDIUM $(100 \mathrm{~mL})$, and HIGH (200mL); sire breeds - Dorset, Merino and White Suffolk; and sex - ewes and wethers. Lambs were confined in individual $0.6 \mathrm{~m} \times 1.2 \mathrm{~m}$ metabolic crates with ad libitum access to drinking water and Lucerne hay, which was replaced daily. All lambs received barley (150g/day). 
Table 1: Nutrient composition of Spirulina and basal diets 1

\begin{tabular}{|c|c|c|c|c|c|}
\hline \multirow{2}{*}{$\begin{array}{l}\text { Chemical } \\
\text { composition }\end{array}$} & \multicolumn{4}{|c|}{ Feed components } & \multirow[t]{2}{*}{ Unit } \\
\hline & Spirulina & $\begin{array}{c}\text { Barley } \\
\text { grain }\end{array}$ & $\begin{array}{c}\text { Lucerne } \\
\text { hay }\end{array}$ & $\begin{array}{l}\text { Ryegrass } \\
\text { pasture }\end{array}$ & \\
\hline Moisture & 4.0 & 6.8 & 9.4 & 55.3 & $\begin{array}{c}\mathrm{g} / 100 \mathrm{~g} \text { fresh } \\
\mathrm{Wt}\end{array}$ \\
\hline $\mathrm{DM}$ & 96.0 & 93.2 & 90.6 & 44.7 & $\begin{array}{c}\text { g/100g Fresh } \\
\text { Wt }\end{array}$ \\
\hline NDF & 32.6 & 18.5 & 36.0 & 22.4 & $\mathrm{~g} / 100 \mathrm{~g} \mathrm{DM}$ \\
\hline NDFn & 30.3 & 17.2 & 33.5 & 20.8 & g/100g DM \\
\hline $\mathrm{ADF}$ & 18.3 & 6.0 & 29.0 & 23.0 & $\mathrm{~g} / 100 \mathrm{~g} \mathrm{DM}$ \\
\hline NFC & 7.9 & 68.7 & 35.2 & 43.5 & $\mathrm{~g} / 100 \mathrm{~g} \mathrm{DM}$ \\
\hline Ash & 9.5 & 3.2 & 6.9 & 11.9 & g/100g DM \\
\hline $\mathrm{EE}$ & 5.9 & 2.0 & 1.9 & 3.0 & g/100g DM \\
\hline $\mathrm{CP}$ & 62.2 & 8.9 & 22.5 & 20.8 & $\mathrm{~g} / 100 \mathrm{~g} \mathrm{DM}$ \\
\hline $\mathrm{ME}$ & 1707.5 & 1723.7 & 1689.3 & 1701.1 & $\mathrm{~kJ} / 100 \mathrm{~g} \mathrm{DM}$ \\
\hline Total carotenoids & 1700 &. & . & . & $\mathrm{mg} / \mathrm{kg}$ \\
\hline beta-carotene & 140000 & . & . & . & $\mu \mathrm{g} / 100 \mathrm{~g}$ \\
\hline Palmitic (16:0) & $\begin{array}{c}25.8- \\
44.9\end{array}$ & . & . & . & $\% \mathrm{FA}$ \\
\hline Palmitoleic (16:1) & $2.3-3.8$ & . & . & . & $\% \mathrm{FA}$ \\
\hline Stearic (18:0) & $1.7-2.2$ & . & . & . & $\% \mathrm{FA}$ \\
\hline Oleic (18:1) & $\begin{array}{c}10.1- \\
16.6\end{array}$ & . & . & . & $\% \mathrm{FA}$ \\
\hline Linoleic (18:2) & $\begin{array}{c}11.1- \\
12.0 \\
\end{array}$ & . & . & & $\% \mathrm{FA}$ \\
\hline
\end{tabular}

${ }_{1}$ Dry matter (DM), neutral detergent fibre (NDF), nitrogen free NDF (NDFn), non-fibrous carbohydrate (NFC), acid detergent fibre (ADF), ether extract (EE), crude protein (CP), and metabolisable energy (ME)

Slaughter occurred at a commercial abattoir (Gretna Quality Meats, Gretna, Tasmania, AUS) on June 9, 2011 and May 24, 2012. On both occasions, Longissimus dorsi et lumborum muscle samples with overlaying subcutaneous fat were removed from each carcass and stored at $-20^{\circ} \mathrm{C}$ until analysis. Prior to analysis, samples were thawed for 24 hours under refrigeration.

IMF was determined using a modified Folch et al. (1957) protocol. This involved using a Ronson homogeniser to homogenise $10 \mathrm{~g}$ of subcutaneous fat free tissue from each sample. Triplicates of approximately $1 \mathrm{~g}$ of the homogenised sample were shaken vigorously for 5 minutes with $5.5 \mathrm{~mL}$ of chloroform: methanol (2:1 vol/vol) solvent. The solution was filtered twice and the combined filtrate was subjected to salt precipitation using $5.5 \mathrm{~mL}$ of potassium chloride $\left(1.34 \mathrm{~mol} / \mathrm{L}^{-1}\right)$ and allowed to separate into two distinct layers. The lower lipid layer was transferred into a preweighed and labelled ceramic crucible and evaporated on a heating block for 1 hour, cooled and placed in a desiccator to dry. The weight of intramuscular fat was calculated as Final wt - Initial crucible wt. This was converted to IMF by: wt(g)/initial tissue subsample(g)*100.

Fat around the Longissimus dorsi et lumborum muscle was removed from each sample and melted in a labelled ceramic crucible in an oven at $100^{\circ} \mathrm{C}$ for 30 minutes. The melted lipid was transferred into $100 \mathrm{~mm}$ capillary tubes (Hirshmann Laborgerate $\AA$, Melbourne, AUS) in triplicates. These were refrigerated prior to FMP evaluation using AOCS (2009) methodology, wherein the temperature at 'slip point' was recorded.

Data were analysed using 'Statistical Analysis System' software (SAS, 2009). Summary statistics were computed with means, standard deviations, and minimum and maximum values examined for data entry errors and outliers. General linear 
models (PROC GLM) procedure (SAS, 2009) was run with Spirulina supplementation level, year, basal diet, sire breed, sex and their second-order interactions fitted as fixed effects and IMF and FMP as dependent variables. Year and other interactions that were not significant were removed from the final model. Tukey's probability pairwise comparison tests were used to distinguish between means at $P$ $<0.05$ threshold of significance.

\section{Results}

It was observed that as the level of Spirulina supplementation increased from LOW to MEDIUM, there were simultaneous decreases in IMF and FMP in comparison with unsupplemented (CONTROL) lambs (Table 2). Although in absolute terms, purebred Merinos appeared to be the leanest with the lowest IMF of $1.59 \%$, sire breed differences in IMF did not reach statistical significance $(P>0.05)$, but FMP did, with Merinos recording the highest FMP of $45.63^{\circ} \mathrm{C}$ (Table 2). Regardless of the level of Spirulina supplementation, sire breed and basal diet, ewe lambs had significantly higher $(P<0.05)$ IMF than wether lambs, but sex differences in FMP were negligible $(P>0.05)$. It was also apparent from Table 2 that ryegrass pasture-fed lambs had significantly lower IMF $(1.65 \%)$ and FMP $\left(43.67^{\circ} \mathrm{C}\right)$ compared to their counterparts on Lucerne hay basal diets.

Table 2: Means \pm standard error of intramuscular fat percentage (IMF) and fat melting point (FMP); probability value ( $P$ values) differences ${ }^{1}$ and levels of significance ${ }^{2}$

\begin{tabular}{|l|l|c|c|}
\hline Factors & Variables & IMF (\%) & FMP $\left({ }^{\circ} \mathbf{C}\right)$ \\
\hline Spirulina supplementation level & CONTROL & $3.29^{\mathrm{a}} \pm 0.22$ & $44.86^{\mathrm{a}} \pm 0.45$ \\
\hline & LOW & $3.18^{\mathrm{b}} \pm 0.43$ & $44.44^{\mathrm{a}} \pm 0.45$ \\
\hline & MEDIUM & $1.98^{\mathrm{c}} \pm 0.13$ & $42.97^{\mathrm{b}} \pm 0.45$ \\
\hline & HIGH & $2.33^{\mathrm{c}} \pm 0.28$ & $43.17^{\mathrm{b}} \pm 0.19$ \\
\hline & P values & 0.007 & $<0.001$ \\
\hline & Black Suffolk & $2.22 \pm 0.34$ & $41.53^{\mathrm{d}} \pm 0.60$ \\
\hline & Dorset & $2.38 \pm 0.21$ & $44.21^{\mathrm{b}} \pm 0.32$ \\
\hline & Merino & $1.59 \pm 0.12$ & $45.63^{\mathrm{a}} \pm 0.33$ \\
\hline & White Suffolk & $2.52 \pm 0.22$ & $43.25^{\mathrm{c}} \pm 0.30$ \\
\hline Sex & Pvalues & 0.285 & $<0.001$ \\
\hline & Ewe & $2.52^{\mathrm{a}} \pm 0.19$ & $43.59 \pm 0.33$ \\
\hline & Wether & $2.12^{\mathrm{b}} \pm 0.16$ & $43.86 \pm 0.26$ \\
\hline Basal diet & P values & 0.050 & 0.283 \\
\hline & Pasture-fed & $1.65^{\mathrm{b}} \pm 0.11$ & $43.67^{\mathrm{b}} \pm 0.31$ \\
\hline & Lucerne hay & $2.93^{\mathrm{a}} \pm 0.19$ & $43.81^{\mathrm{a}} \pm 0.28$ \\
\hline & P values & $<0.001$ & $<0.001$ \\
\hline
\end{tabular}

${ }^{1}$ Column means within a fixed effect bearing different superscripts significantly differ $(P<0.05) .{ }^{2}$ Levels of significance: $P>0.05$ (n.s), $P<0.05\left({ }^{*}\right), P<0.01\left(^{* *}\right)$, and $P<0.001\left(^{* * *}\right)$.

There were significant differences in IMF and FMP due to interactions between Spirulina supplementation level, basal diet, sex and sire breed (Figures 1-3). It was apparent that regardless of supplementation level, relatively poorer quality meat with high IMF was produced when the lambs were on a basal diet of Lucerne hay, but a combination of ryegrass grazing with increased MEDIUM to HIGH levels of Spirulina supplementation led to a 
consistent reduction in intramuscular fat

(Fig. 1a).

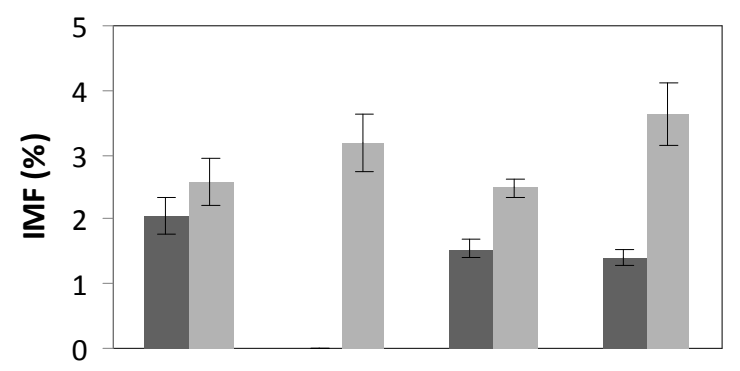

a

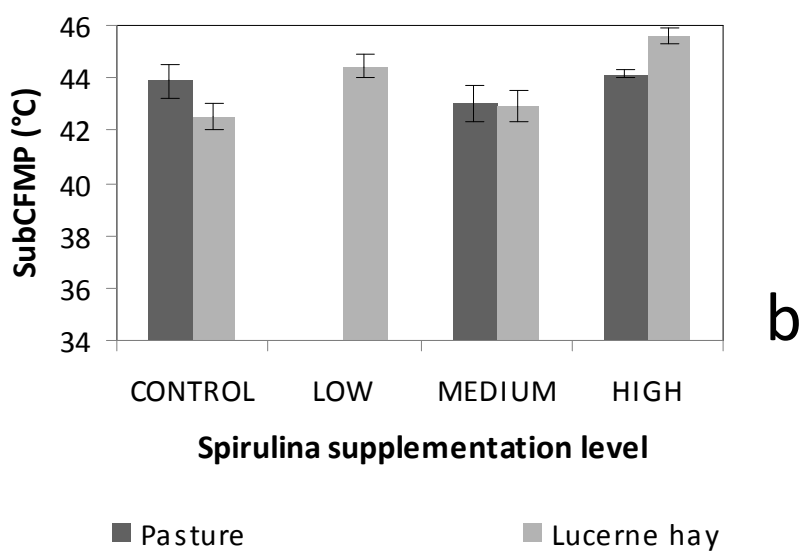

Figure 1: Spirulina supplementation level and diet interaction on a) IMF - intramuscular fat percentage $(P<0.001)$; and b) FMP - subcutaneous fat melting point $(P<0.001)$

Pasture-fed ewes supplemented at MEDIUM and HIGH Spirulina levels had higher IMF than the CONTROL treatment group. Ewe IMF with HIGH Spirulina supplementation level and Lucerne hay basal diet exceeded all other IMF percentages (Fig. 2a). Ewe FMP with MEDIUM Spirulina supplementation levels and pasture basal diet were the lowest. Ewe FMP was highest with MEDIUM and HIGH Spirulina supplementation and Lucerne hay basal diet. Wether FMP with LOW and HIGH Spirulina supplementation and Lucerne hay basal diet exceeded CONTROL and MEDIUM Spirulina supplementation levels (Fig. 2b). 

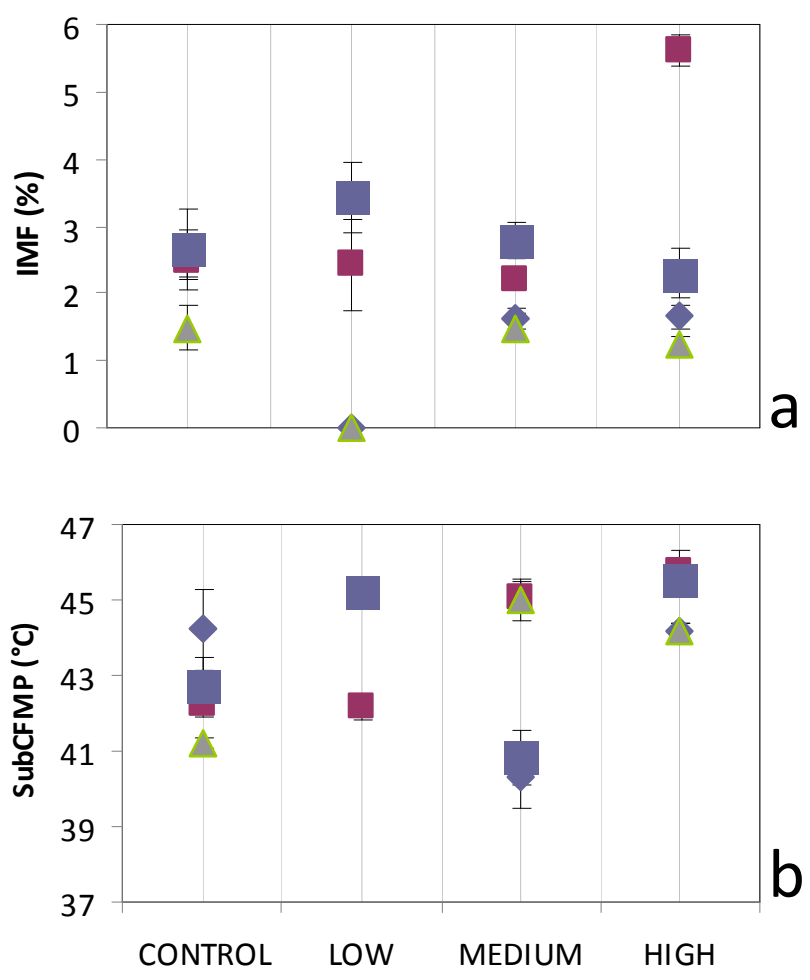

Spirulina supplementation level

$\triangle$ Ewe: Pasture
$\triangle$ Wether: Pasture
Wether: Lucerne hay

Figure 2: Spirulina supplementation level, sex and diet interactions on a) IMF intramuscular fat percentage $(P<0.001)$; and b) FMP -fat melting point $(P<0.001)$

FMP in pasture-fed Black Suffolk-sired lambs was highest with HIGH Spirulina supplementation level. In pasture-fed Merino-sired lambs, FMP was highest with MEDIUM Spirulina supplementation level. Dorset-sired lambs on Lucerne hay basal diet had higher FMP with Spirulina supplementation compared to the CONTROL group. Lucerne hay-fed White Suffolk-sired lambs had the highest FMP with HIGH Spirulina supplementation level (Fig. 3.). 


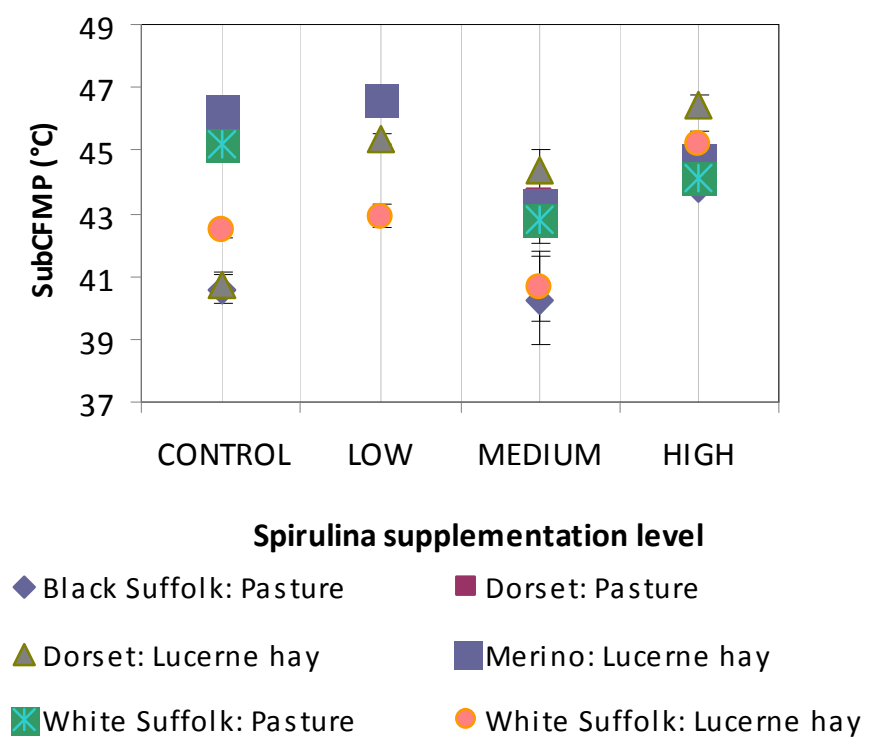

Figure 3: Spirulina supplementation level, diet and sire breed interactions on FMP -fat melting point $(P<0.001)$

\section{Discussion}

The observation of simultaneous decreases in IMF and FMP as the level of Spirulina supplementation increased from LOW to MEDIUM when compared to the unsupplemented group of lambs (CONTROL), is consistent with similar observations in another experiment where lambs were supplemented with degummed crude canola oil (Flakemore et al. 2014a, 2014b).The observed decrease in FMP suggests a possible increase in unsaturated fatty acids (UFA) and a decrease in saturated fatty acids (SFA) and softer fat probably due to Spirulina's naturally high beta-carotene content (Table 1; Holman \& Malau-Aduli, 2013). Retinoic acid, a metabolite of beta-carotene, plays a role in ruminant stearoyl Co-A desaturase enzyme activity and expression that drives SFA desaturation in the rumen (Siebert et al., 2000). These changes in SFA/UFA differ from supplementation trials involving Spirulina fed to rabbits (Peiretti \& Meineri, 2011). However, rabbits are pseudoruminants, unlike lambs, where dietary UFA in Spirulina is relatively unprotected from biohydrogenation by rumen microflora.

Dietary intake has a marked effect on ruminant IMF. During periods of low dietary intake, there is a marked reduction in IMF compared to periods of high dietary intake (Geesink \& Zerby, 2010, Hopkins et al., 2007, Roberts et al., 2007). This study's findings, however, diverge from this preconception. This may have arisen from our experimental design in which Lucerne hay fed lambs were confined to stalls. This confinement would have restricted energy expenditure to well below that of equivalent pasture run lambs. We suggest this difference in energy utilisation would be reflected in our IMF findings.

High FMP is associated with elevated SFA and lowered UFA concentrations. Dietary factors influence ruminant adipose deposits in terms of fatty acid composition (Webb \& O'Neill, 2008), although to a lesser extent than in monogastrics (Bas \& Morand-Fehr, 2000). Dietary fatty acids influence adipose fatty acid composition and this influence is limited by rumen biohydrogenation of UFA (Bas \& MorandFehr, 2000). However, linolenic acid, a fatty acid associated with pastures, is relatively resistant to this biohydrogenation compared to other fatty acids (Bas \& Morand-Fehr, 2000). Furthermore, dietary linolenic acid has been reported to increase ruminant UFA levels, such as eicosapentaenoic acid, docosahexaenoic acid and docosapentaenoic acid (Raes et al., 2004). Subsequently, lambs fed pasture basal diets are expected to have greater UFA and lower FMP compared to those fed Lucerne hay. Aurousseau et al. (2007) 
observed similar results with lambs finished on both pasture and concentrates where UFA was lower in pasture-fed lambs than in their stall fed counterparts on concentrates.

IMF is influenced by nutrition, particularly dietary lipid content. This premise would explain the observed differences between MEDIUM and HIGH Spirulina supplementation levels with Lucerne hay basal diet. However, our findings with ryegrass basal diets are not easily explainable because of the tendency of dietary lipid to be partitioned more towards subcutaneous fat deposition than IMF (Kempster, 1981). Holman et al. (2012) reports of an increase in lamb body condition score with increased Spirulina supplementation level in these same lambs. However, body condition score is a subjective assessment of the degree of subcutaneous fat deposition. Hence, it is possible that the dietary lipid sourced from Spirulina was partitioned primarily to the subcutaneous fat depot. Therefore, Spirulina supplementation with ryegrass basal diet resulted in leaner lamb meat compared to CONTROL lambs.

Ruminant sire breed effects on IMF (McPhee et al., 2008, Pethick et al., 2010) and FMP (Aurousseau et al., 2007, Costa et al., 2009, Malau-Aduli et al., 2000) have been widely reviewed previously. The influences of sex on IMF have also been reported by Dervishi et al., (2012), McPhee et al., (2008) and Pethick et al., (2010). Our findings align with these observations.

\section{Acknowledgements}

The Australian Wool Education Trust (AWET) and The University of Tasmania (UTAS) funded this research with grants and postgraduate top-up scholarships for which the authors are grateful to both AWET and UTAS. The contributions of Chris Gunn, Barrie Wells, Florence Malecot, Loudella Deladerriere, John Otto and Will Bignell during the sheep breeding, feeding trials and laboratory analysis are highly appreciated.

\section{Conclusion}

Lambs grazed on a basal diet of ryegrass had significantly lower IMF and FMP compared to their counterparts fed Lucerne hay. As the level of Spirulina supplementation of lambs increased from LOW to MEDIUM, there were simultaneous decreases in IMF and FMP in comparison with unsupplemented lambs. Ewe lambs had significantly higher IMF than wether lambs, but sex differences in FMP were negligible.

\section{References}

1. AOCS - American Oil Chemists' Society (2009). Slip melting point ISO Standard. AOCS Official Method Cc 3b-92.

2. Aurousseau, B., Bauchart, D., Galot, A.L., Prache, S., Micol, D. \& Priolo, A., (2007). Indoor fattening of lambs raised on pasture: 2. Influence of stall finishing duration on triglyceride and phospholipid fatty acids in the longissimus thoracis muscle. Meat Science, 76: 417-427.

3. Bas, P. \& Morand-Fehr, P., (2000). Effect of nutritional factors on fatty acid composition of lamb fat deposits. Livestock Production Science, 64: 61-79.

4. Costa, R.G., Malveira Batista, A.S., de Azevedo, P.S., Ramos do Egypto Queiroga, R.d.C., Madruga, M.S. \& de Araujo Filho, J.T., (2009). Lipid profile of lamb meat from different genotypes submitted to diets with different energy levels. Brazilian Journal of Animal Science, 38: 532-538.

5. Dervishi, E., Joy, M., Alvarez-Rodriguez, J., Serrano, M. \& Calvo, J.H., (2012). The forage type (grazing versus hay pasture) fed to ewes and the lamb sex affect fatty acid profile and lipogenic gene expression in the longissimus muscle of suckling lambs. Journal of Animal Science, 90: 54-66.

6. Flakemore, A.R., McEvoy, P.D., Balogun, R.O., Malau-Aduli, B.S., Nichols, P.D. \& Malau-Aduli, A.E.O., (2014a). Degummed crude canola oil supplementation affects fat depot melting points in purebred and firstcross Merino sheep. Animal and Veterinary Sciences, 2: 75-80.

7. Flakemore, A.R., Balogun, R.O., McEvoy, P.D., Malau-Aduli, B.S., Nichols, P.D. \& Malau-Aduli, A.E.O., (2014a). Genetic variation in intramuscular fat of prime 
lambs supplemented with varying concentrations of degummed crude canola oil. International Journal of Nutrition and Food Sciences, Vol. 3, Issue 3, (In Press).

8. Folch, J., Lees, M. \& Sloane-Stanley, G.H., (1957). A simple method for the isolation and purification of total lipids from animal tissues. Journal of Biological Chemistry, 226: 497-509.

9. Holman, B.W.B., Kashani, A. \& MalauAduli, A.E.O., (2012). Growth and body conformation responses of genetically divergent Australian sheep to Spirulina (Arthrospira platensis) supplementation. American Journal of Experimental Agriculture, 2: 160-173.

10. Holman, B.W.B. \& Malau-Aduli, A.E.O., (2013). Spirulina as a livestock supplement and animal feed. Journal of Animal Physiology and Animal Nutrition, 97: 615623.

11. Hopkins, D.L., Stanley, D.F., Toohey, E.S., Gardner, G.E., Pethick, D.W. \& van de Ven, R., (2007). Sire and growth path effects on sheep meat production 2. Meat and eating quality. Australian Journal of Experimental Agriculture, 47: 1219-1228.

12. Kempster, A.J., (1981). Fat partition and distribution in the carcasses of cattle, sheep and pigs: A review. Meat Science, 5: 83-98.

13. Malau-Aduli, A.E.O., Edriss, M.A., Siebert, B.D., Bottema, C.D.K. \& Pitchford, W.S., (2000). Breed differences and genetic parameters for melting point, marbling score and fatty acid composition of lot-fed cattle. Journal of Animal Physiology and Animal Nutrition, 83: 95-105.

14. McPhee, M.J., Hopkins, D.L. \& Pethick, D.W., (2008). Intramuscular fat levels in sheep muscle during growth. Australian Journal of Experimental Agriculture, 48: 904-909.

15. Peiretti, P.G. \& Meineri, G., (2011). Effects of diets with increasing levels of Spirulina platensis on the carcass characteristics, meat quality and fatty acid composition of growing rabbits. Livestock Science, 140: 218-224.

16. Raes, K., De Smet, S. \& Demeyer, D., (2004). Effect of dietary fatty acids on incorporation of long chain polyunsaturated fatty acids and conjugated linoleic acid in lamb, beef and pork meat: a review. Animal Feed Science and Technology, 113: 199-221.

17. Roberts, A.J., Paisley, S.I., Geary, T.W., Grings, E.E., Waterman, R.C. \& MacNeil, M.D., (2007). Effects of restricted feeding of beef heifers during the postweaning period on growth, efficiency, and ultrasound carcass characteristics. Journal of Animal Science, 85: 2740-2745.

18. SAS, (2009). Statistical Analysis System. SAS Institute, Cary, North Carolina, USA, version 9.2 .

19. Siebert, B.D., Pitchford, W.S., Kuchel, H., Kruk, Z.A. \& Bottema, C.D.K., (2000). The Effect of $\beta$-carotene on desaturation of ruminant fat. Asian-Australasian Journal of Animal Science, 13: 185-188.

20. Webb, E.C. \& O'Neill, H.A., (2008). The animal fat paradox and meat quality. Meat Science, 80: 28-36.

21. Woods, V.B. \& Fearon, A.M., (2009). Dietary sources of unsaturated fatty acids for animals and their transfer into meat, milk and eggs: A review. Livestock Science, 126: 1-20. 